\title{
Investigation of Insulation Materials for Future Radioisotope Power Systems (RPS)
}

\author{
Peggy A. Cornell ${ }^{1}$, Frances I. Hurwitz ${ }^{2}$, David L. Ellis ${ }^{3}$ \\ NASA Glenn Research Center, Cleveland, Ohio, 44135 \\ and \\ Paul C. Schmitz ${ }^{4}$ \\ Vantage Partners, LLC, Cleveland, Ohio, 44135
}

\begin{abstract}
NASA's Radioisotope Power System (RPS) Technology Advancement Project is developing next generation high temperature insulation materials that directly benefit thermal management and improve performance of RPS for future science missions. Preliminary studies on the use of multilayer insulation (MLI) for Stirling convertors used on the Advanced Stirling Radioisotope Generator (ASRG) have shown the potential benefits of MLI for space vacuum applications in reducing generator size and increasing specific power $(\mathrm{W} / \mathrm{kg}$ ) as compared to the baseline Microtherm HT (Microtherm, Inc.) insulation. Further studies are currently being conducted at NASA Glenn Research Center (GRC) on candidate MLI foils and aerogel composite spacers. This paper presents the method of testing of foils and spacers and experimental results to date.
\end{abstract}

\section{Nomenclature}

$\begin{array}{ll}\mathrm{Al}_{2} \mathrm{O}_{3} & =\text { aluminum oxide } \\ \mathrm{ASC} & =\text { Advanced Stirling Convertor } \\ \mathrm{ASRG} & =\text { Advanced Stirling Radioisotope Generator } \\ \mathrm{atm} & =\text { atmosphere } \\ \mathrm{DAQ} & =\text { data acquisition } \\ \mathrm{Fe}_{2} \mathrm{O}_{3} & =\text { iron (III) oxide (ferric oxide) } \\ \mathrm{GPHS} & =\text { General Purpose Heat Source } \\ \mathrm{GRC} & =\text { Glenn Research Center } \\ \mathrm{ID} & =\text { inside diameter } \\ \mathrm{MLI} & =\text { multilayer insulation } \\ \mathrm{MPS} & =\text { Moulded Pipe Section } \\ \mathrm{Na}_{2} \mathrm{O} & =\text { sodium oxide } \\ \mathrm{OD} & =\text { outside diameter } \\ \mathrm{RPS} & =\text { Radioisotope Power System } \\ \mathrm{SiO}_{2} & =\text { silicon dioxide } \\ \mathrm{TEOS}_{\mathrm{ZrO}} & =\text { tetraethyl orthosilicate } \\ \mathrm{ZrO}_{2} & =\text { zirconium dioxide (zirconia) }\end{array}$

\footnotetext{
${ }^{1}$ Physicist, Thermal Energy Conversion Branch, 21000 Brookpark Rd/MS 301-2, AIAA Senior Member.

${ }^{2}$ Senior Materials Research Engineer, Polymers Branch, Structures and Materials Division, 21000 Brookpark $\mathrm{Rd} / \mathrm{MS}$ 49-3.

${ }^{3}$ Materials Research Engineer, Advanced Metallics Branch, 21000 Brookpark Rd/MS 49-1, AIAA Member.

${ }^{4}$ Thermal Systems Engineeer, Thermal Energy Conversion Branch, 21000 Brookpark Rd/MS 301-2.
} 


\section{Introduction}

$\mathrm{T}$ He Advanced Stirling Radioisotope Generator (ASRG) is under development by the Department of Energy and Lockheed Martin Space Systems Company. It is comprised of two Advanced Stirling Convertors (ASC) which are being developed by an integrated team of Sunpower and the National Aeronautics and Space Administration's Glenn Research Center (GRC). The ASC development, funded by NASA's Science Mission Directorate, started as a technology development effort in 2003 and has since evolved through progressive convertor builds and successful testing to demonstrate high conversion efficiency, low mass, and capability to meet long-life Radioisotope Power System (RPS) requirements. The objective of the ASRG's insulation package is twofold; to minimize the loss of thermal energy from the Plutonium-238 General Purpose Heat Source (GPHS) to the environment and to act as a passive safety device in the event of single convertor stoppage. In the latter case, the insulation would permanently shrink to allow a sufficient heat leak, ensuring that the iridium cladding in the GPHS never exceeds its design temperature.

Preliminary studies have been done on the use of multilayer insulation (MLI) in the ASRG. These studies show the potential benefits of MLI for space vacuum applications in reducing generator size and increasing specific power (W/kg) as compared to the baseline Microtherm HT (Microtherm, Inc.) insulation. Thermal losses from the Microtherm HT insulation currently used in the ASRG are estimated to exceed $25 \%\left(62.3 \mathrm{~W}_{\text {th }}\right.$ on the ground (1 atm Argon) ) and $15 \%\left(37.8 \mathrm{~W}_{\text {th }}\right)$ in a vacuum of the total $244.0 \mathrm{~W}_{\text {th }}$ generated by the GPHS ${ }^{1}$. Studies show these losses can be reduced through the substitution of MLI for the Microtherm HT currently used in the ASRG. A schematic of the ASRG and its insulation package is shown in Fig. 1.

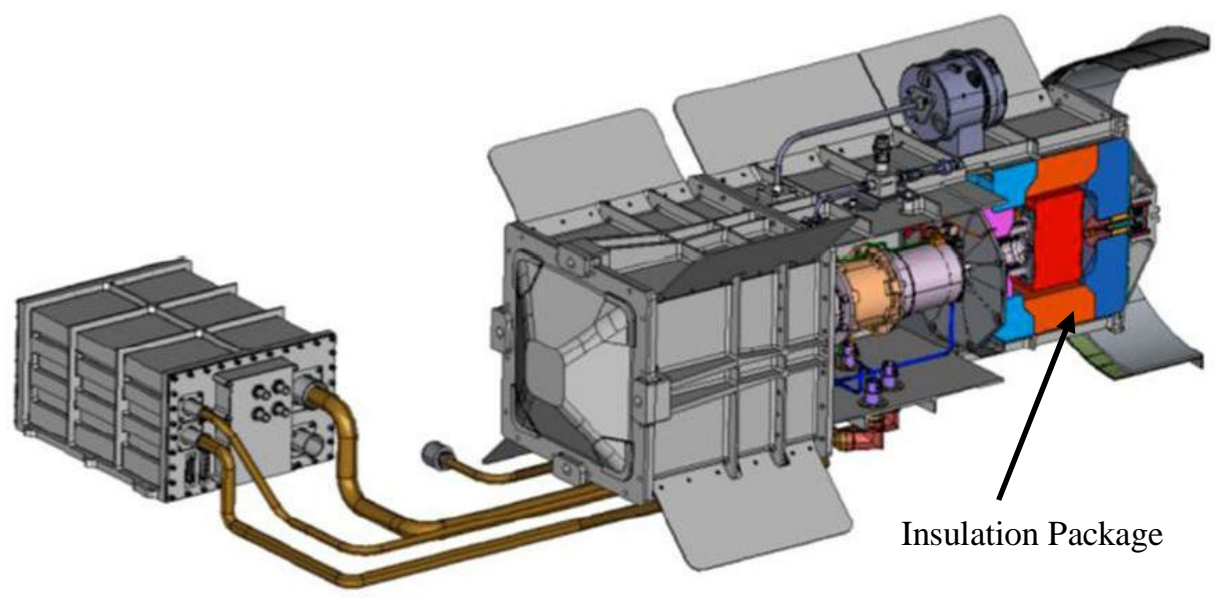

Figure 1. Advanced Stirling Radioisotope Generator featuring insulation package.

The MLI consists of several layers of closely spaced, highly reflective shields, or foils, which are placed perpendicular to the heat flow direction. These low emissivity foils provide a thermal high resistance to radiative heat transfer between layers. To avoid direct contact between the foils, and therefore heat conduction between the sheets, low-conductivity, nonmetallic spacers are used. A sketch of a typical multilayer insulation is shown in Figure 2.

The theoretical thermal conductivity of MLI (using

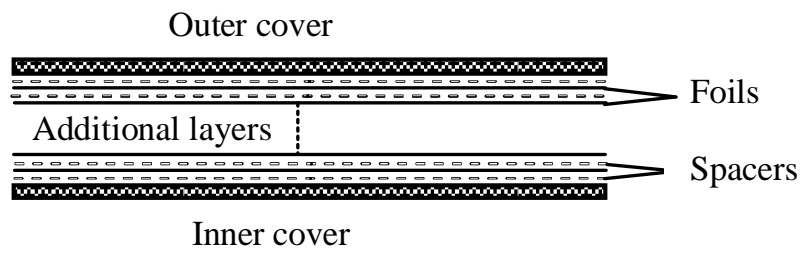

Figure 2. Sketch of a typical multilayer insulation. Foils are denoted by a solid line and spacers by a dashed line. nickel foils and $\mathrm{ZrO}_{2}$ spacers) has been found to be approximately two orders of magnitude less than that of fibrous bulk insulations at $1000^{\circ} \mathrm{C}$ in a vacuum environment ${ }^{2}$. To help better quantify the characteristics and potentially increase the temperature range of state-of-the-art MLI, a development effort is underway to expand our experimental test rig capabilities, identify, test and analyze candidate materials, and optimize data collection and thermal modeling at GRC. This effort is key in that insulation materials directly benefit thermal management and could improve performance of RPS for future science missions. 


\section{Experimental Testing}

\section{A. Insulation Test Rig and Test Methodology}

The design goal of the experimental test rig was to establish onedimensional heat flow through an insulation sample to compare MLI candidates including foil/aerogel hybrid insulations for future RPS. A secondary goal was to configure the rig for relatively convenient interchangeability of the test samples and addition of instrumentation as needed. The MLI rig and test station can be seen in Fig. 3.

The test rig consists of a heat source and a vertical MLI stack surrounded by a Microtherm Moulded Pipe Section (MPS) holder. The heat source is a HeatWave Laboratory Model \#102104 heater enclosed in a custom housing. The inside diameter (ID) of the MPS holder slips over the outside diameter (OD) of the custom heater housing and encloses the heater and MLI stack. The MPS holder insulates the MLI stack and the heater, minimizing heat loss in the radial direction, as well as optically encloses the test sample. The MPS holder is made of a microporous silica insulation with a nominally 4" ID and 4.5" OD that is wrapped in E-Glass cloth for easy handling. Its rated thermal conductivity in air is $0.034 \mathrm{~W} / \mathrm{mK}$ at a mean temperature of $800{ }^{\circ} \mathrm{C}$, the highest temperature tested by the manufacturer ${ }^{3}$. The heater, which is made of tungsten, has a three layer heat shield on the back side to minimize heat loss in the downward direction. Its heating elements are covered by a molybdenum plate that acts as a heat spreader. The heater is rated to operate at $1100{ }^{\circ} \mathrm{C}$ continuously in vacuum. Installation of the MPS holder around the tungsten heater is shown in Fig. 4. The vertical MLI

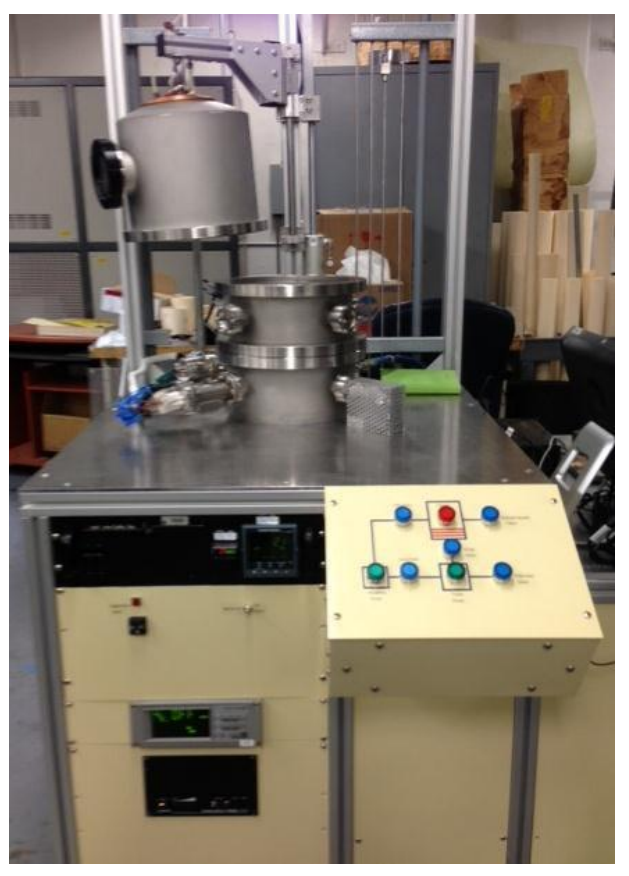

Figure 3. MLI rig and test station. test sample stack is constructed by alternately layering either ceramic fabric or paper spacers with or without aerogel impregnation between metal foils.
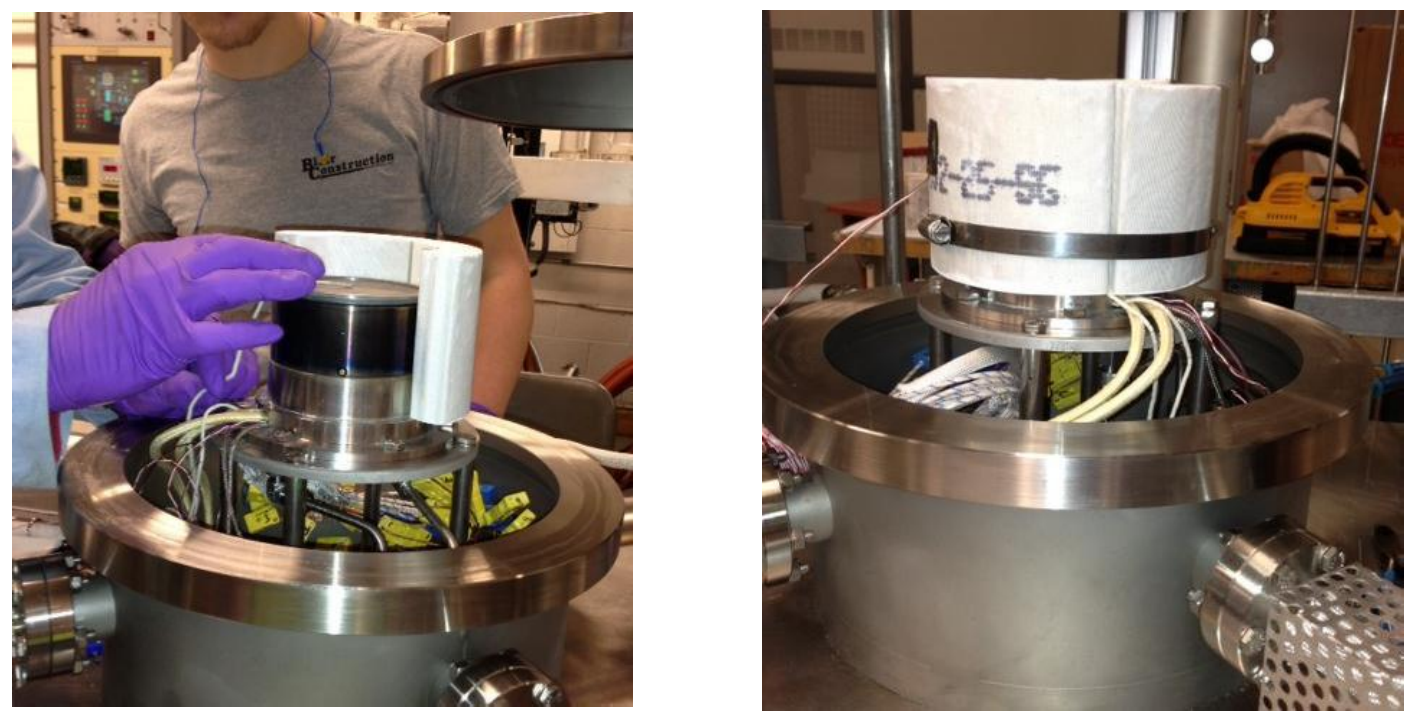

Figure 4. MPS holder installed around tungsten heater in MLI Rig. Image on left shows MPS holder being installed around the heater. Image on right shows MPS holder in its testing configuration. 
An RdF Model 27036-3 heat flux sensor with integrated Type $\mathrm{T}$ thermocouple was adhered to the top foil in the MLI stack using OMEGABOND ${ }^{\circledR} 200$ high thermal conductivity two-part epoxy. The temperature and heat flux of the outside of the holder and backside of the heater were measured using RdF Model 27036-1 and 27036-3 heat flux sensors, respectively. The heat flux sensors are limited to a maximum operating temperature of $260{ }^{\circ} \mathrm{C}$. The bottom heat flux sensor is consistently the hottest and therefore limits the maximum reference temperature of the test rig to approximately $625{ }^{\circ} \mathrm{C}$. Figure 5 shows the heat flux sensor affixed to the outside of the MPS holder.

The entire assembly was mounted in a stainless steel bell jar. The bell jar is evacuated using a Leybold Model TMP $1000 \mathrm{C}$ turbopump to a pressure

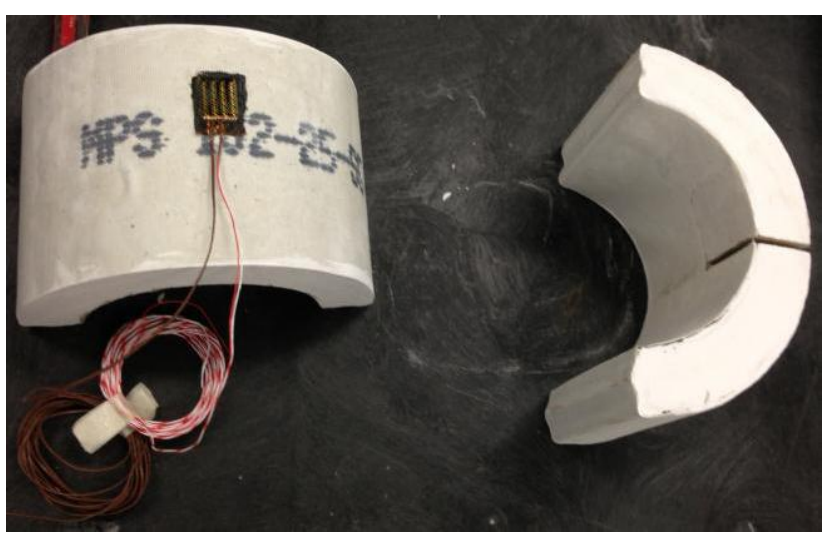

Figure 5. Heat flux sensor installed on the side of the Microtherm MPS holder.

less than $8 \times 10^{-6}$ torr to ensure that convection does not play a significant role in the heat transfer.

The top of the bell jar is water cooled to maintain a constant sink temperature of $20{ }^{\circ} \mathrm{C}$. The un-cooled sides of the bell jar that are outside of the view factor of the top foil minimally heat up during testing. The maximum temperature of these sidewalls was measured to be less than $35^{\circ} \mathrm{C}$ by a combination of reference thermocouples and IR imaging of the exterior of the sidewalls.

An Ohio Semitronics PC8-002-01D DC watt transducer and a variable frequency AC watt transducer measures the electrical power supplied to the heater and permits a power balance calculation and determination of the potential heat losses through thermal shorts and other means not accounted for by the three heat flux sensors, e.g., loss through the copper leads for the heater power and loss through the thermocouples.

The signals from the sensors were collected using ICP DAS Model I-7011 data acquisition (DAQ) modules. The modules convert the analog signals to digital signals and send the data over a local area network to the DAQ computer. A custom-written DAQ program is utilized to record data every 60 seconds. This interval is sufficient to give adequate statistical data on the measurements.

During testing, data were considered to be at steady state and test conditions at thermal equilibrium when the test environment pressure was less than $8 \times 10^{-6}$ torr and the temperature of the top foil remained constant within $3{ }^{\circ} \mathrm{C}$ per hour. The top foil thermocouple was used to determine thermal equilibrium since it was observed to be the last of the test environment thermocouples to reach thermal equilibrium. The thermocouple that defined the reference temperature, or test rig temperature, during testing is located above the heater and below the hottest (bottom) foil.

\section{B. Candidate Materials}

The Advanced Stirling Convertor has an upper temperature limit of approximately $850{ }^{\circ} \mathrm{C}$ based on material life requirements. The ASCs in the Advanced Stirling Radioisotope Generator currently operate below this maximum temperature due to improved overall power output (reduced heat losses through the insulation) at $760{ }^{\circ} \mathrm{C}$. Using the ASC material limits of a nickel heat acceptor at $850{ }^{\circ} \mathrm{C}$ temperature, the temperature of the inner surface of the insulation is typically $100{ }^{\circ} \mathrm{C}$ greater, or $950{ }^{\circ} \mathrm{C}$. The candidate MLI foils and spacers under consideration for testing must perform effectively within this temperature range. The candidate foils, along with their respective material properties, are listed in Table I.

Table I. Candidate foils for MLI testing.

\begin{tabular}{|l|c|c|c|c|}
\hline \multicolumn{1}{|c|}{ Metal } & $\begin{array}{c}\text { Melting } \\
\text { Point }\end{array}$ & $\begin{array}{c}\text { Emissivity/ } \\
\text { Temp }\left({ }^{\circ} \mathrm{C}\right)\end{array}$ & Note & $\begin{array}{c}\text { Measured Emissivity/ } \\
\text { Temp }\left({ }^{\circ} \mathrm{C}\right)\end{array}$ \\
\hline Tantalum & $3000{ }^{\circ} \mathrm{C}$ & $0.14-0.30 / 727-2930$ & unoxidized & $0.0922 / 25$ \\
\hline $\begin{array}{l}\text { Nickel }- \\
\text { Niobium }\end{array}$ & $\begin{array}{c}1170{ }^{\circ} \mathrm{C} \\
(\text { eutectic })\end{array}$ & $\begin{array}{c}\mathrm{Ni}=0.05-0.19 / 38-1000 \\
\mathrm{Nb}=0.12 / 1000\end{array}$ & $\begin{array}{c}\text { unoxidized }- \text { only } \\
\text { first layer } \mathrm{Nb}\end{array}$ & $\begin{array}{c}\text { Nickel }=0.0258 / 25 \\
\text { Niobium }=0.052 / 25\end{array}$ \\
\hline Molybdenum & $261{ }^{\circ} \mathrm{C}$ & $0.06-0.18 / 38-1093$ & unoxidized & $\mathrm{TBD}$ \\
\hline Gold & $1063{ }^{\circ} \mathrm{C}$ & $0.02-0.03 / 38-1093$ & Polished & TBD \\
\hline
\end{tabular}


Emissivity testing was performed at room temperature on the tantalum, nickel and niobium candidate foils to verify their known emissivity values. The measurements were obtained using an Infrared Reflectometer Model DB100 from Gier Dunkle Instruments, Inc. Reflectivity was measured and recorded at various locations on each sample, allowing us to obtain the average emissivity of each foil. The reflectometer was calibrated to the gold and black standard values of $\mathrm{R}=0.976$ and 0.089 , respectively. These measured emissivity values are also shown in Table I.

The candidate spacer materials under consideration, which have advanced insulating properties compared to zirconia spacers that have been used in the past, include APA-2 alumina

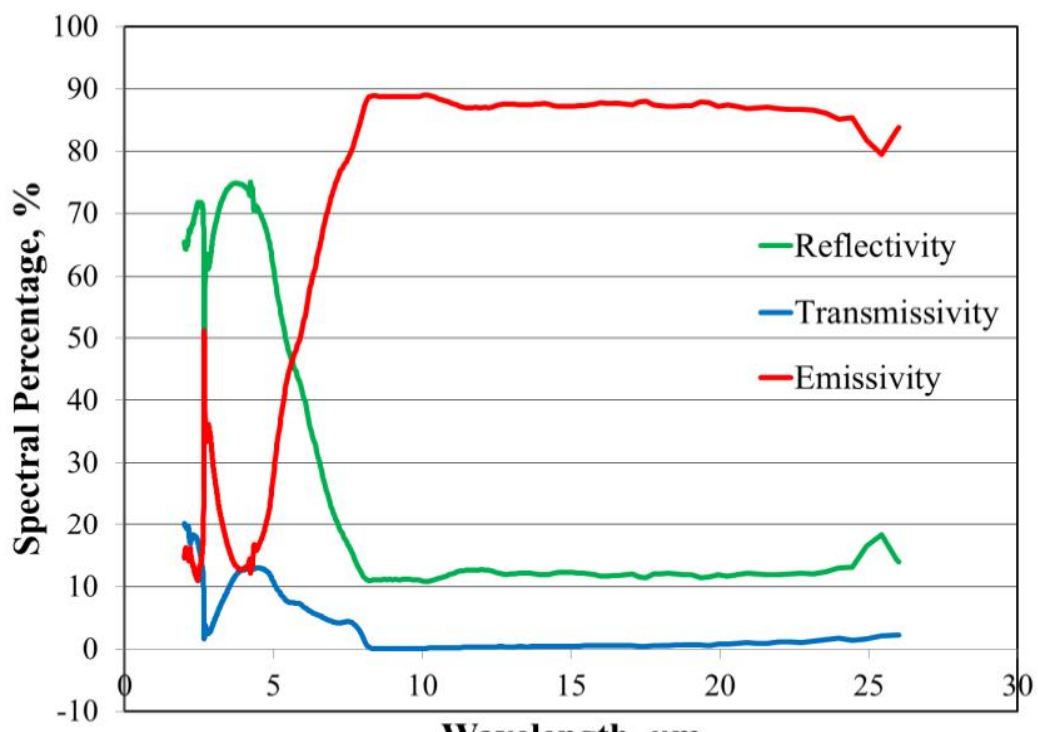

Wavelength, $\mu \mathrm{m}$

Figure 6. Spectral properties of APA-2 paper with aerogel. paper (Zircar Ceramics, Inc.), Astroquartz silica fiber fabric (JPS Composite Materials), Fiberfrax 972AH alumina paper (Unifrax, LLC) and Saffil paper (Saffil, Ltd.). As shown in Fig. 6, spectral properties of the candidate spacer materials are a primary factor in material selection for testing. Further consideration includes commercial availability and physical characteristics such as thickness and density. The physical and thermal characteristics, as well as composition, of the current candidate spacers are shown in Table II and their respective microstructures are shown in Figs. 7 - 10.

Characterization of insulation materials has substantially progressed and material scientists at Glenn Research Center are presently studying aerogel materials with increased temperature capability and lower densities compared with state of the art polymer-based insulating materials. Composites such as those currently under consideration impregnated with aerogel offer potential as spacers between MLI foils.

Table II. Candidate spacers for MLI testing.

\begin{tabular}{|c|c|c|c|c|}
\hline Ceramic Reinforcement & $\begin{array}{l}\text { Thickness } \\
(\mathrm{mm})\end{array}$ & $\begin{array}{l}\text { Density } \\
(\mathrm{g} / \mathrm{cc})\end{array}$ & $\begin{array}{l}\text { Upper Use } \\
\text { Temperature }\end{array}$ & Composition (\%) \\
\hline APA-2 Paper & 1.25 & 0.11 & $1650^{\circ} \mathrm{C}$ & $86 \mathrm{Al}_{2} \mathrm{O}_{3}, 10 \mathrm{SiO}_{2}, 4$ other oxides \\
\hline Fiberfrax 972AH & 0.8 & 0.192 & $1176^{\circ} \mathrm{C}$ & $\begin{array}{c}\text { 47-52 } \mathrm{Al}_{2} \mathrm{O}_{3}, 48-53 \mathrm{SiO}_{2},<0.5 \mathrm{Na}_{2} \mathrm{O}, \\
<0.5 \mathrm{Fe}_{2} \mathrm{O}_{3}\end{array}$ \\
\hline $\begin{array}{l}\text { Astroquartz (503 plain } \\
\text { weave without binder) }\end{array}$ & 0.11 & 2.2 & $1070^{\circ} \mathrm{C}$ & $99.99 \mathrm{SiO}_{2}$ \\
\hline Saffil Paper & $0.5,1.0$ & $0.5-0.7$ & $1600^{\circ} \mathrm{C}$ & $\begin{array}{c}95-97 \mathrm{Al}_{2} \mathrm{O}_{3}, 3.0-5.0 \mathrm{SiO}_{2},<0.5 \text { trace } \\
\text { elements }\end{array}$ \\
\hline
\end{tabular}

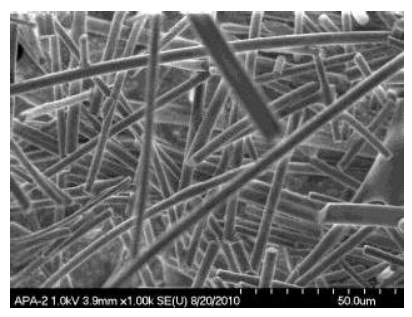

Figure 7. microstructure

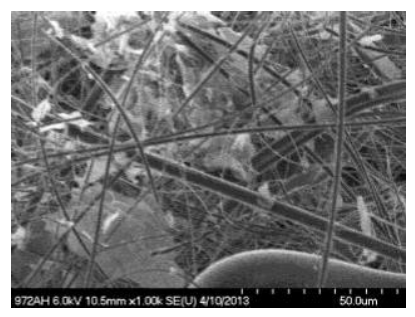

Figure 8. Fiberfrax 972AH microstructure

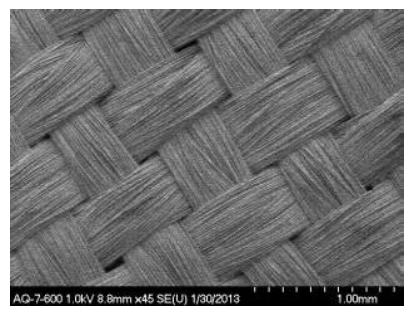

Figure 9. Astroquartz fabric microstructure

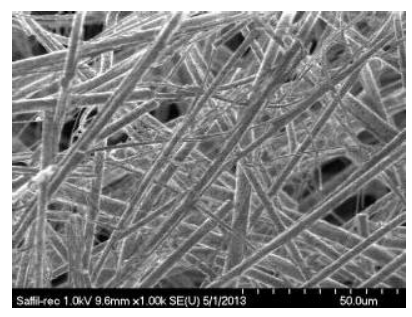

Figure 10. Saffil paper microstructure 

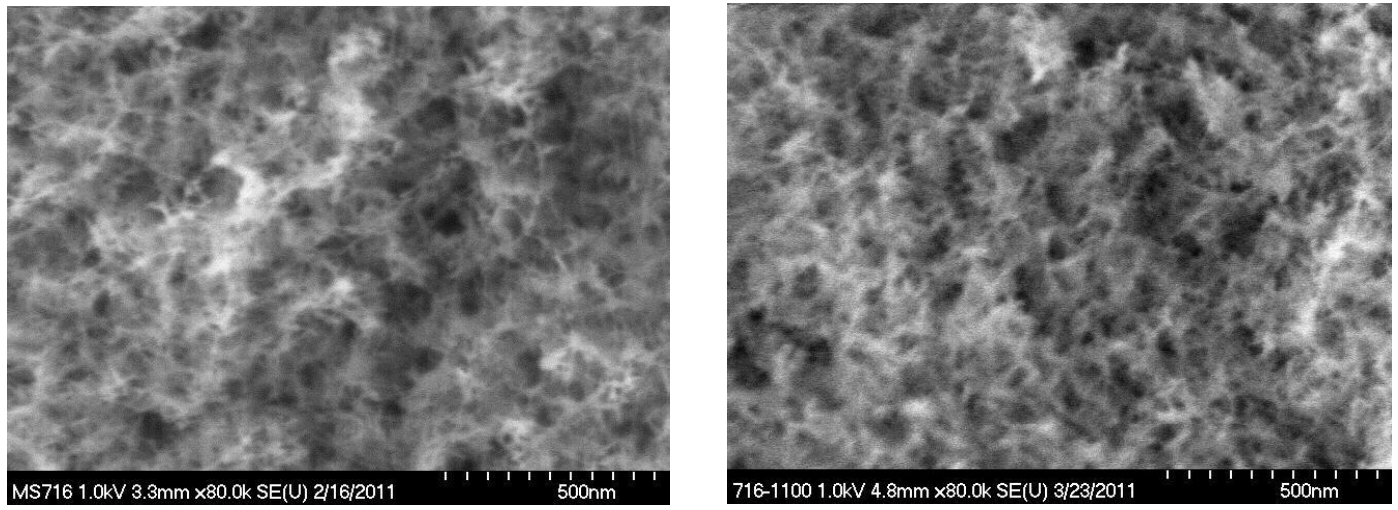

Figure 11. Microstructure of the as-supercritically dried aluminosilicate aerogel before and after 20 minutes of exposure at $1100{ }^{\circ} \mathrm{C}$. Image on left shows before drying (surface area is 415 $\mathrm{m}^{2} / \mathrm{g}$ ). Image on right shows after drying (surface area is $266 \mathrm{~m}^{2} / \mathrm{g}$ ).

Aerogels are mesoporous structures with interconnecting pores and high surface areas; the pore walls are comprised of thin struts that provide a lengthy and tortuous path limiting solid conduction from foil to foil. In an application with any gaseous environment, gas convection is limited by the small-scale pore structure; in both atmosphere and vacuum, extinction of radiation heat transfer takes place by absorption ${ }^{4}$ and is wavelength and temperature dependent. The effective thermal conductivity also is expected to be influenced by the emissivity of the adjacent foils ${ }^{5}$.

Although numerous studies have been conducted on silica aerogels, aerogels can be synthesized using a wide variety of elements, and their upper use temperature is limited by their chemical composition. Hence, polymeric aerogels are limited by the decomposition temperature of the particular polymer $\left(>400^{\circ} \mathrm{C}\right.$ for some polyimides). Silica aerogels sinter above $700^{\circ} \mathrm{C}$, losing their high surface area and becoming less insulating. The group at NASA Glenn Research Center has developed aluminosilicate aerogels which maintain high surface areas and mesoporous structures to temperatures of $1100-1200^{\circ} \mathrm{C}$ through the reaction of boehmite and tetraethyl orthosilicate (TEOS), in which the surface area and pore structure can be controlled by the choice of boehmite precursor and the synthesis parameters ${ }^{6,7}$. The aluminosilicate aerogels in the present study utilize an aluminum to silicon ratio of 3 to 1 , the ratio found in mullite.

Microstructure of the as-supercritically dried aerogel, and the same aerogel after 20 minutes of exposure at $1100^{\circ} \mathrm{C}$, is shown in Fig. 11 . The surface area decreases from 415 to $266 \mathrm{~m}^{2} / \mathrm{g}$ on exposure, and the pore volume decreases from 0.67 to $0.44 \mathrm{~cm}^{3} / \mathrm{g}$. A mesoporous structure is maintained, with the average pore diameter changing from 7.44 to 8.15 nm.

Because of the fragile nature of the aluminosilicate aerogel monoliths, our team at GRC has developed techniques for incorporating these into composites, which can be reinforced using ceramic fabrics, papers, or felts. The work presented here focuses on the use of APA-2 alumina paper. Composites also have been fabricated using Astroquartz silica fiber fabric or Fiberfrax 972AH alumina paper. The composites remain flexible (Fig. 12), which would be advantageous in forming an MLI around the GPHS. The APA- 2 composite has a density of 0.15 $\mathrm{g} / \mathrm{cm}^{3}$, as compared with $0.3428 \mathrm{~g} / \mathrm{cm}^{3}$ for Microtherm HT. The

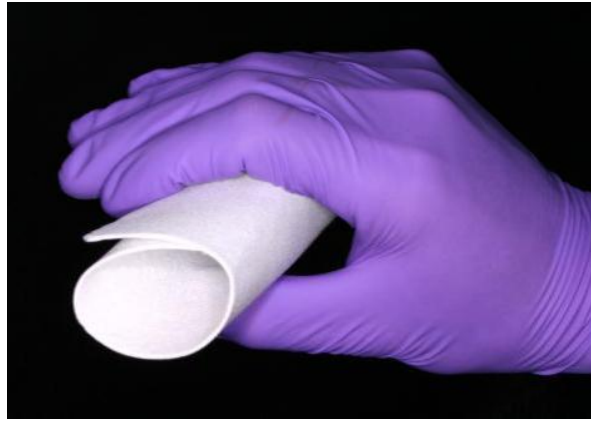

Figure 12. Aerogel composite reinforced with APA-2 alumina paper.

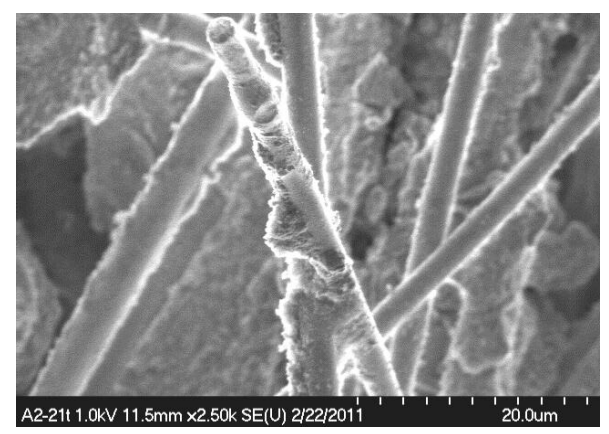

Figure 13. Microstructure of APA-2 with aerogel composite showing good wetting of aerogel to fibers. aluminosilicate aerogel bonds well to the alumina fibers (see Fig. 13), averting the spalling of aerogel particles seen in some commercial materials. 


\section{Modeling}

A Thermal Desktop ${ }^{\circledR}$ model of the insulation sample and surrounding environment was created to estimate the thermal performance of the test foils (see Fig. 14). The model includes the following test rig components; foils with temperature dependent properties, spacers, heat source and test chamber (approximated as a single isothermal boundary).

Currently, poor correlation exists between the test results and the model, therefore, modification of both the test rig and the model are underway. Heat losses, such as edge effects (radiation from the edges of the MLI stack), were present primarily due to the small test sample size (4" diameter).

Several heat transfer paths and mechanisms can strongly influence the model predictions and associated uncertainty and error propagation. One testing attribute being investigated is to experimentally determine the effect of

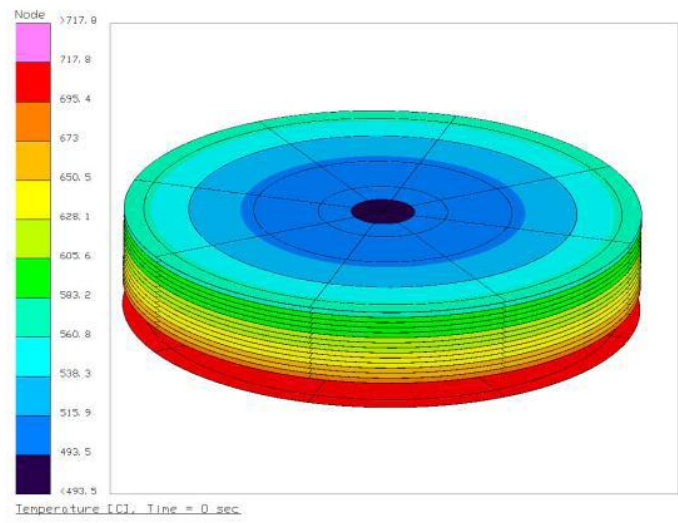

Figure 14. MLI model results using Thermal Desktop®.

spacer thickness on MLI performance. Thick or multiple spacer layers allow for the placement of thermocouples between foil layers with minimum physical perturbation of the foils. Test runs are also underway with thermocouples at only the hot and cold sides of the stack as well as each layer of the stack to evaluate the influence of radial heat transfer along the thermocouple leads. Once the heat transfer paths are identified, the MLI test rig will be redesigned in an attempt to mitigate heat leaks, improve data fidelity and reduce associated error. An exploded view of the current test setup, generated through modeling tools, is shown in Fig. 15 with respective callouts in Table III.

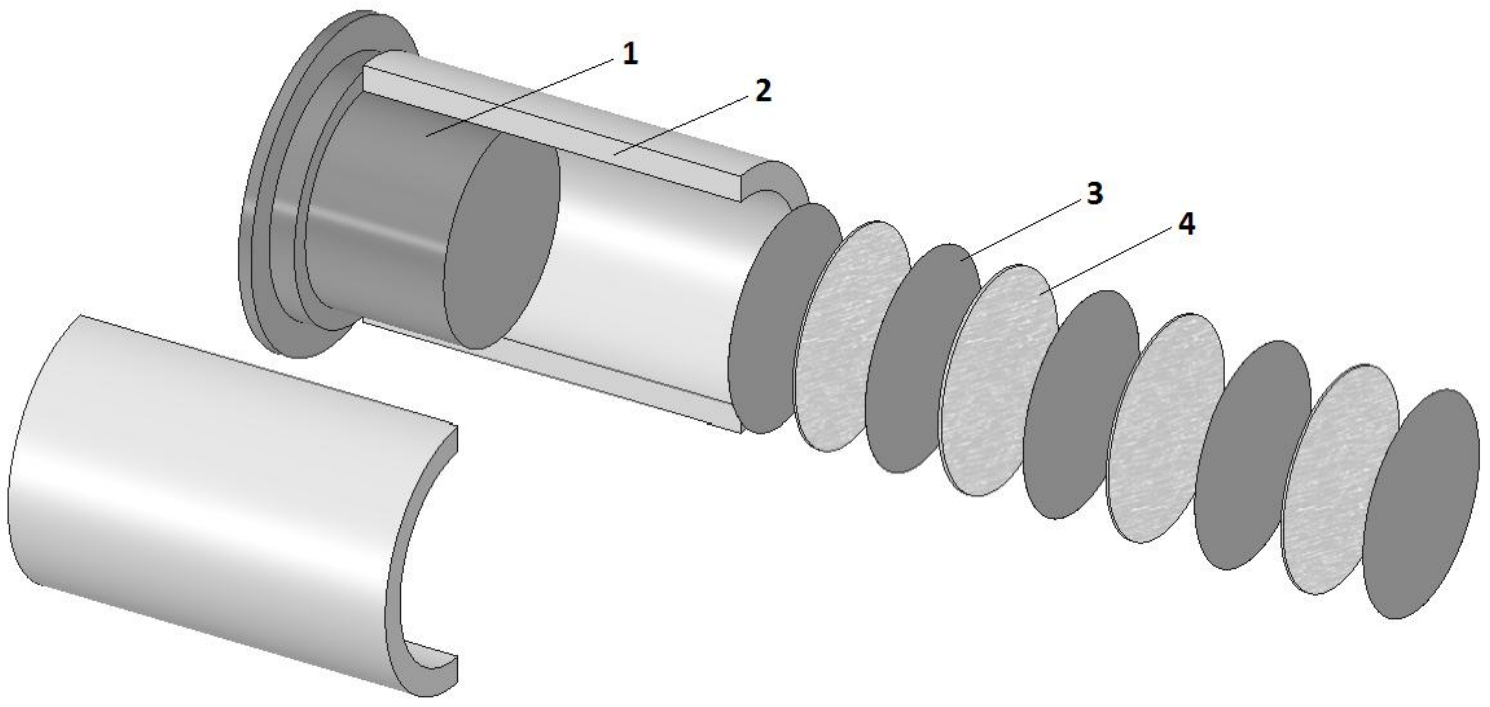

Figure 15. Exploded view of the primary test section components and MLI test sample.

Table III. Locations of the primary test section components and MLI test sample as shown in Fig. 15.

\begin{tabular}{|c|l|}
\hline Callout & \multicolumn{1}{c|}{ Description } \\
\hline 1 & Heater assembly \\
\hline 2 & MPS holder \\
\hline 3 & Foil \\
\hline 4 & Spacer \\
\hline
\end{tabular}




\section{Experimental Results}

\section{A. Tantalum Foils with APA-2 Alumina Paper}

The first multilayer insulation run consisted of tantalum foils and APA-2 alumina paper spacers. The thickness of the MLI stack was approximately 0.5 ". Temperatures within the MLI test rig were increased by approximately $50{ }^{\circ} \mathrm{C}$ every $12-24$ hours until the data were considered to be at steady state and test conditions at thermal equilibrium (pressure was less than $8 \times 10^{-6}$ torr and temperature of the top foil remained constant within $3{ }^{\circ} \mathrm{C}$ per hour).

As seen in Fig. 16, the maximum operating temperature that can be reached with this foil and spacer combination is approximately $600{ }^{\circ} \mathrm{C}$. This is because the heat flux sensors that were utilized are limited to a maximum temperature of $260{ }^{\circ} \mathrm{C}$. The bottom heat flux sensor near the heater is consistently the hottest and therefore limits the maximum reference temperature of the test rig to approximately $625{ }^{\circ} \mathrm{C}$.

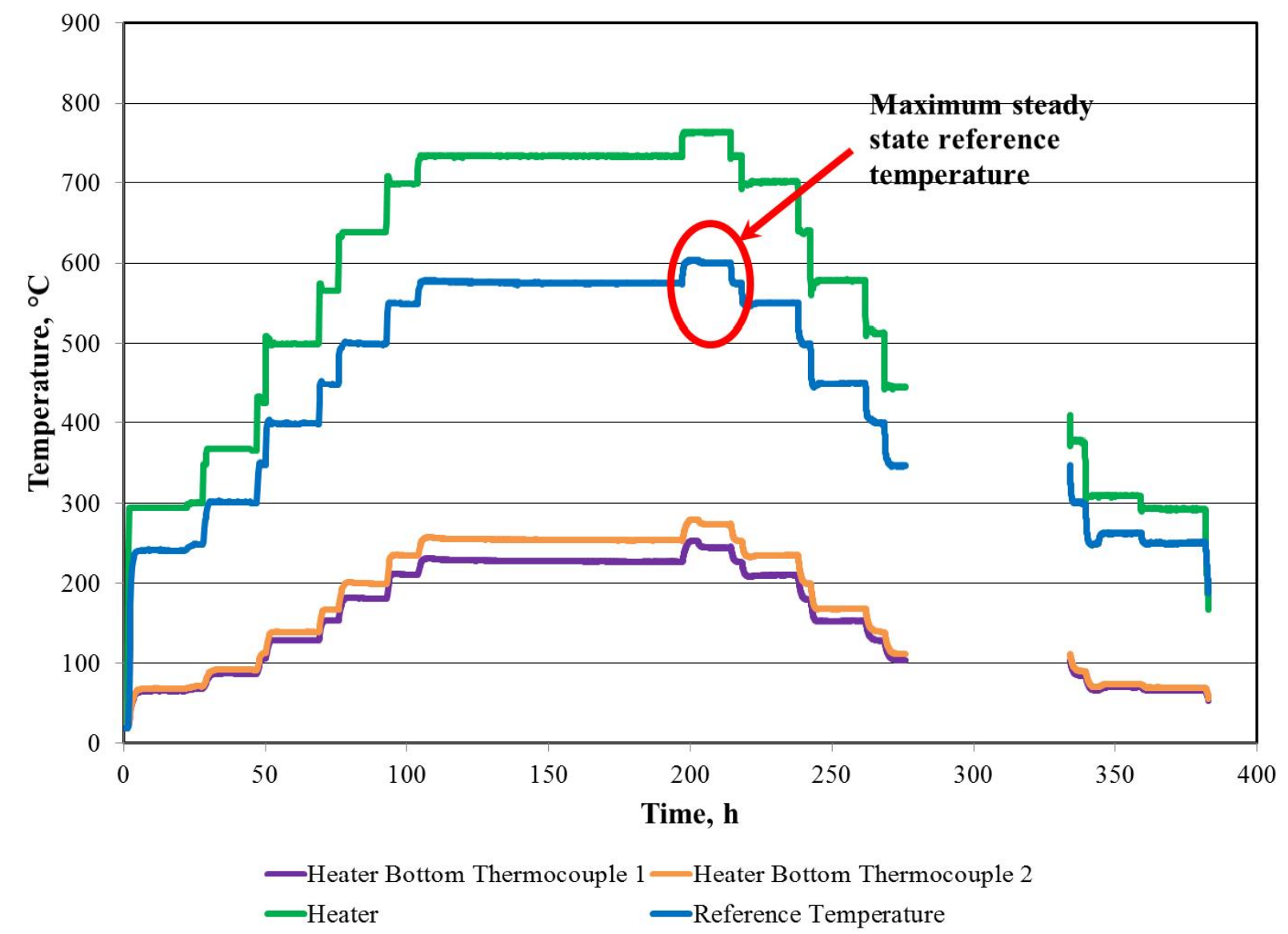

Figure 16. A typical time versus temperature plot for the tantalum foils with APA-2 alumina paper. The data at maximum test rig temperature is circled.

\section{B. Tantalum Foils with APA-2 Alumina Paper Impregnated with Aluminosilicate Aerogel}

The subsequent MLI run consisted of five tantalum foils and eight APA-2 alumina paper spacers impregnated with aluminosilicate aerogel. The test rig conditions remained the same as the previous test, and the maximum temperature reached was approximately $620^{\circ} \mathrm{C}$. Test results of the tantalum foils and APA-2 with aerogel were similar to tantalum foils and APA-2 alone. The exception was that the temperature of the top (coldest) tantalum foil within the stack was approximately $40{ }^{\circ} \mathrm{C}$ less (at a test rig temperature of $600{ }^{\circ} \mathrm{C}$ ) when the APA-2 paper was impregnated with aerogel compared with APA-2 paper alone (see Fig. 17). The data captured in GRC's MLI test rig indicated that the composite spacer with aluminosilicate aerogel reduced heat transfer compared to the composite spacer without aerogel. Further testing and analysis is required to confirm repeatability of the results and to determine the basis for the temperature difference. 


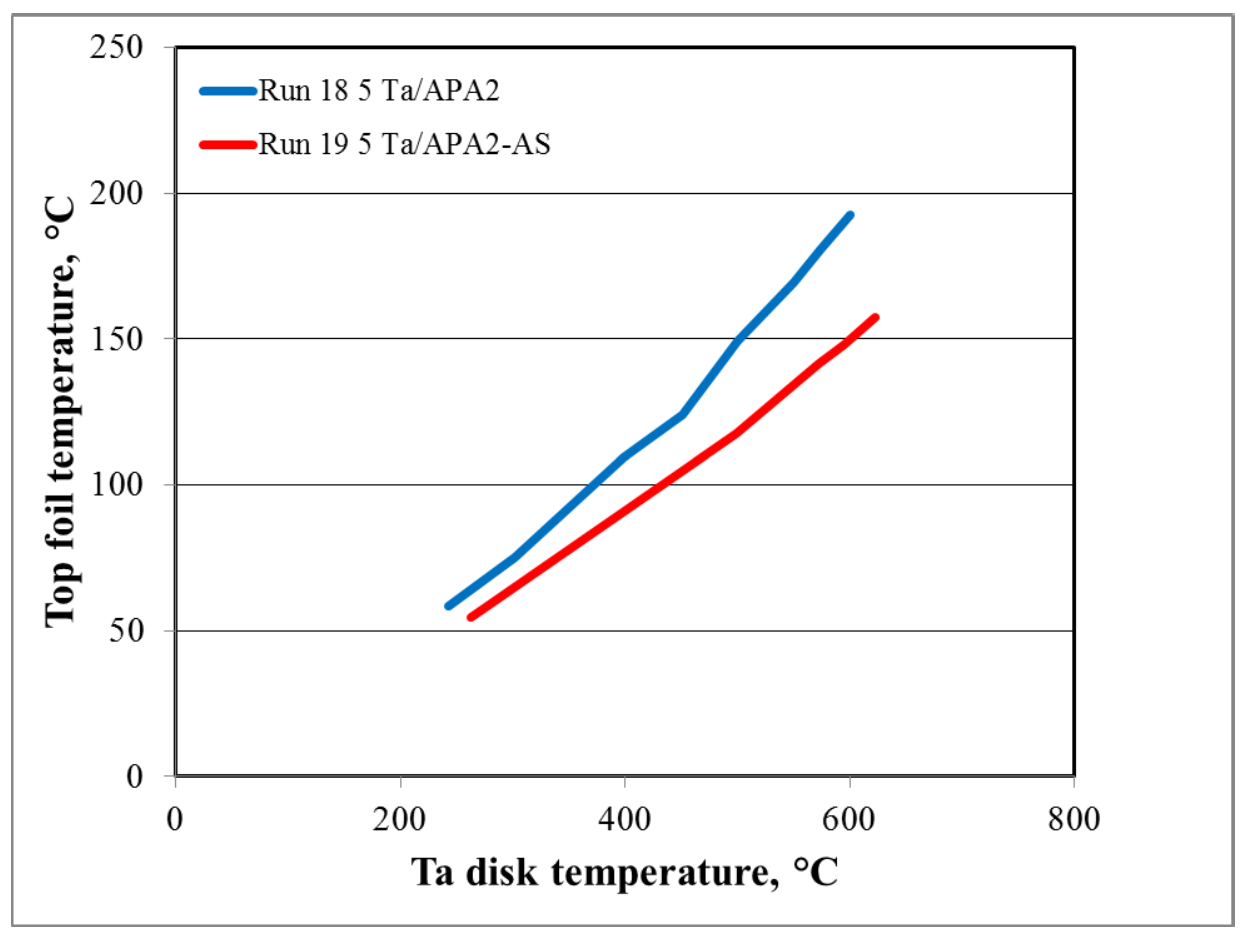

Figure 17. Comparison of tantalum foils with APA-2 paper and tantalum foils with APA-2 paper with aerogel. The blue plot represents the tantalum/APA-2 temperatures and the red plot represents the tantalum/APA2 with aerogel temperatures. The $x$-axis displays reference temperatures and the $y$-axis displays the coldest foil temperature (top of MLI stack).

\section{Conclusion}

Insulation materials have a significant effect on decreasing the thermal losses and increasing specific power $(\mathrm{W} / \mathrm{kg}$ ) of radioisotope power systems. To help better quantify the characteristics and potentially increase the temperature range of state-of-the-art MLI, a development effort is underway to expand our experimental test rig capabilities, identify, test and analyze candidate materials, and optimize data collection and thermal modeling at GRC. Heat flow through insulation samples was achieved in the newly-developed MLI test rig and thermal measurement methods and predictions are progressing. Characterization of insulation materials has substantially advanced and aerogel materials with increased operating temperature and decreased density are being studied for use as composite spacers in MLI. Future testing will consider foil/spacer combinations that are suitable in high temperatures, can remain flexible to form an effective MLI around the General Purpose Heat Source of the ASRG, and are thin and low in density to potentially reduce generator size and increase specific power as compared to the baseline Microtherm HT insulation.

\section{Acknowledgments}

This work is funded through the NASA Science Mission Directorate. Any opinions, findings, conclusions or recommendations expressed in this article are those of the authors and do not necessarily reflect the views of the National Aeronautics and Space Administration. The authors wish to acknowledge the people who made this effort possible including Katie Shaw for providing considerable analytical and modeling guidance; Haiquan Guo for her materials expertise and composite fabrication; Adrienne Veverka, Jesse Bierer and Grant Feichter for their technical dedication to our experimental testing; Don Jaworske for enabling our emissivity testing; and Terry O’Malley, Lee Mason and Duane Beach for supporting this effort under the Radioisotope Power System (RPS) program. 


\section{References}

${ }^{1}$ Wang, X.J., Fabanich, W.A., and Schmitz, P.C., "Advanced Stirling Radioisotope Generator Thermal Power Model in Thermal Desktop SINDA/FLUENT Analyzer," Proceedings of the Tenth International Energy Conversion Engineering Conference (IECEC 2012), Atlanta, GA, August 2012, AIAA 2012-4060.

${ }^{2}$ Thermo Electron Corp, "Application of Multi-Foil Insulation to the Brayton Isotope Power System and Conceptual Design of Multi-Foil Insulation for the Flight System (Phase I)," U.S. Department of Commerce Preliminary Design Review Document TE420910076, June 1976.

${ }^{3}$ Promat High Performance Insulation Microtherm ${ }^{\circledR}$ MPS Moulded Pipe Section brochure from http://www.microthermgroup.com/landingpage/assets/TDS_MICROTHERM_MPS_V1-EN.pdf.

${ }^{4}$ Heinemann, U., R. Caps, et al. (1996). "Radiation-Conduction Interaction: An Investigation on Silica Aerogels." Int. J. Heat Mass Transfer 39(10): 2115-2130.

${ }^{5}$ Scheuerpflug, P., R. Caps, et al. (1985). "Apparent Thermal Conductivity of Evacuated SiO2-Aerogel Tiles under Variation of Radiative Boundary Conditions." Int. J. Heat mass Transfer 28(12): 2299-2306.

${ }^{6}$ Hurwitz, F. I., H. Guo, et al. (2010). Tailoring of Boehmite-Derived Aluminosilicate Aerogel Structure and Properties: Influence of Ti Addition. MRS Fall Meeting, Boston, MA, Materials Research Society.

${ }^{7}$ Hurwitz, F. I., H. Guo, et al. (2012). "Influence of Ti Addition on Boehmite-Derived Aluminum Silicate AErogels: Structure and Properties." J Sol-Gel Sci Technol 64(3): 756-764. 